\title{
EXPLORING INCLUSIVE EDUCATION ACROSS EUROPE: SOME INSIGHTS FROM THE EUROPEAN AGENCY STATISTICS ON INCLUSIVE EDUCATION
}

\author{
Joacim Ramberg ${ }^{1}$ \\ European Agency for Special Needs and Inclusive Education, Sweden \\ Department of Special Education, Stockholm University, Sweden
}

\section{Amanda Watkins}

European Agency for Special Needs and Inclusive Education, United Kingdom

\begin{abstract}
The European Agency Statistics on Inclusive Education (EASIE) work focuses upon the collection and analysis of longitudinal, comparative national data related to inclusive education systems and learners with officially recognised special educational needs (SEN) among its 31 member countries. In this article, the EASIE work is discussed in relation to the key concepts of presence, placement, participation and progress within inclusive education systems. The findings of the EASIE work indicate differences and variations between countries in how they respond to all learners' rights to an inclusive education. There are substantial differences in the identification rates of learners identified as having SEN across countries. In addition, the EASIE data shows that all countries use some form of fully segregated settings for some learners, indicating a gap between inclusive education as a societal goal and practice. Possibilities for future, more comprehensive comparative data collection concerning inclusive education systems are discussed.
\end{abstract}

Keywords: inclusion; inclusive education; educational policy, data collection, comparative, European education

\section{Introduction}

In a historically relative short period of time, inclusive education has been established as a global field of educational research that has the potential to inform policy and practice at different structural levels (e.g., cross-national, national, regional, local and individual) (Slee, 2018).

\footnotetext{
${ }^{1}$ Correspondence: European Agency for Special needs and Inclusive Education, Østre Stationsvej 33, DK-
} 5000, Odense C, Denmark. E-mail: joacim@european-agency.org 
Despite the rapidly growing and well-established evidence base on which inclusive education is founded, it can be seen that within the research society there is still not a consensus on its fundamental basis or what existing definitions - that depend on contextual, cultural, historical and methodological aspects - should be used in work (Florian, 2014a; Meijer and Watkins, 2016).

From one perspective, inclusive education can be understood as a societal, equitable, democratic educational goal, that all concerned actors must strive towards (UNESCO, 2009a). It can also be understood as a methodological/organisational issue in which provision at different levels within the education system is organized in an inclusive manner, in order to achieve societal educational goals in line with social justice and participation for all its actors (Haug, 2017).

Therefore, as a concept and research object, definitions of inclusive education take different shapes depending on what perspective, starting point, target group and methodological approaches are being taken (Artiles, Kozleski, Dorn, \& Christensen, 2006; Göransson \& Nilholm, 2014).

As an overall societal goal, inclusive education is more clearly expressed as including many shared ideal elements taken from a rights-perspective that are expressed in policy and guidelines from different international organisations (Hardy \& Woodcock, 2015). At the international level, these rights are clearly expressed within the United Nations Convention on the Rights of Persons with Disabilities (United Nations, 2006), as well as the Sustainable Development Goal for Education (SDG4) that highlights the need to: 'Ensure inclusive and equitable quality education and promote lifelong learning opportunities for all' (UNESCO, 2015, p. 7). The World Forum on Education Incheon declaration argues that: 'Inclusion and equity in and through education is the cornerstone of a transformative education agenda, and we therefore commit to addressing all forms of exclusion and marginalization, disparities and inequalities in access, participation and learning outcomes. No education target should be considered met unless met by all' (UNESCO, 2015, p. 7).

Overall, the UNESCO 2017 Guidelines for Inclusion in Education, interprets these rights as meaning: 'Every learner matters and matters equally' (UNESCO, 2017, p. $12)$.

At the European Union level, the European Commission's Education and Training Monitor 2015 report argues that: 'Effective education is about inclusiveness, ensuring every citizen has an opportunity to develop their talents and to feel part of a shared future. Building effective education and training systems requires a focus on inclusion as part and parcel of the broader quest for excellence, quality and relevance.' (European Commission, 2015, p. 7).

This argument is built upon in the Education and Training Monitor 2018 report, that states: 'EU Leaders proclaimed in 2017 the European Pillar of Social Rights, as a guide towards upwards employment and social convergence, and towards promoting better opportunities for youth in Europe. The very first principle of the Social Pillar identifies inclusiveness and relevance of education as a key element to impact on people's lives and enable to support the European construction in the 21 st century' (European Commission, 2018, p. 26).

Later in 2018, the Council Recommendation on Promoting Common Values, Inclusive Education, and the European Dimension of Teaching argues that: Ensuring effective equal access to quality inclusive education for all learners, including those of migrant origins, those from disadvantaged socio-economic backgrounds, those with special needs and those with disabilities - in line with the Convention on the Rights of Persons with Disabilities - is indispensable for achieving more cohesive societies' (European Union, 2018, p. 6). 
However, the way these overall guidelines are expressed in the national policies of European countries differs considerably (European Agency, 2015). There are considerable national, and regional differences regarding what is meant by inclusive education as an organizational or methodological issue. As discussed by Haug (2017), but also supported by the wider work of the European Agency for Special Needs and Inclusive Education (Watkins \& Meijer, 2016) within all countries there are, to differing extents, gaps between policy formulations and the actual realization of inclusive education.

There are myriad obstacles and difficulties related to comparative educational studies, especially concerning complex issues such as inclusive education, as demonstrated by D'Alessio and Cowan (2013). The differences between countries' policy contexts and definitions of educational concepts such as special educational needs, special needs education, or inclusive education underpins the fact that international and/or European comparative studies exploring inclusive education are difficult to conduct and implement (European Agency, 2018a). Nevertheless, the importance of access to comparative data to inform policy makers' work remains.

\section{Data collection to inform inclusive education policy development}

The European Agency for Special Needs and Inclusive Education is an independent, self-governing, non-profit European organisation. It was established in 1996 as an initiative of the Danish Government, endorsed by the member states' Education Ministers, in response to the need for a permanent and systematic structure for European collaboration in its field. It is the only European body maintained by its member countries with the specific mission of helping them improve the quality and effectiveness of their inclusive provision for all learners. The Agency has a legal basis at European level (Decision no. 791/2004/EC). It is one of six European institutions recognised as contributing to the European integration process through its activities in the field of education and training.

The Agency's work with member countries combines the perspectives of policy, practice and research to provide member countries and policy-makers at the European level with evidence-based information and recommendations on implementing inclusive education.

Since 1999, at the request of member countries, the Agency has systematically collected quantitative data on special needs education. However, the focus of data collection, as well as the methods have changed significantly in that time.

A recurring issue for policy makers and researchers within the field of inclusive education is - and has for a long time been - how the degree of inclusiveness within education systems can be measured, evaluated and thus developed. As stated by Loreman, Forlin, and Sharma (2014a): 'In the absence of a unified definition of what inclusion is, attempts to measure or compare such a complex equity issue are, unsurprisingly, challenging' (p. 4).

From a European policy perspective, it is an absolute necessity to have access to valid and reliable data in order to be able to develop educational policy and guidelines at the regional, national and European level that can contribute to more inclusive education systems (European Agency, 2014a). The importance of such data collection is emphasised within SDG4 and as a human rights issue, is anchored in the Convention on the Rights of Persons with Disabilities, where it is stated that State Parties requires to: '...collect appropriate information, including statistical and research data, to enable them to formulate and implement policies to give effect to the present Convention' (United Nations, 2006, Article 31).

Previous work within the European Agency also emphasises this rights-based perspective, stating that it is important to know who is included and who is excluded from schooling, as without some way of counting, there can be no accountability (European 
Agency, 2011a). The need to collect data that can be used to classify and measure aspects of the experience of different groups of learners within an education system is also emphasized by Hollenweger (2014). She argues that within the educational context, classification of learners is necessary as policy makers need information about who has access to education, who is excluded from schooling and how learners with special educational needs (SEN) may be discriminated against. This argument is in line with Florian (in European Agency, 2014a) who argues that policy development concerning inclusive education is not possible without reliable data that can be used as the basis for guiding future reforms. This in turn requires reliable and systematic collection of data of both qualitative and quantitative character, which can be used to evaluate changes and development over time within countries, but also by comparing development and patterns of change between countries.

As argued by Watkins and Ebersold (2016), having access to such information can be seen as a prerequisite for change, development and improvement of the education system. The importance of having access to relevant and reliable data for policy makers is clear: 'There is widespread awareness that evidenced-based policy-making is critical for the long-term development of inclusive education systems' (p. 229).

This is supported by UNESCO, who encourage member states to: '... collect and use relevant data on all categories of the excluded to better develop education policies and reforms for their inclusion, as well as to develop national monitoring and evaluation mechanisms' (UNESCO, 2009b, p. 19). Likewise, the World Health Organisation (WHO) (2011) recommend countries to develop their existing quantitative data collection on issues that can inform policy makers on the barriers for inclusion of learner's possibilities to participate in education.

However, what this data might be and how it can be obtained at national and European levels appears to be far more complex and challenging. There are no clear answers to key questions such as what the relevant issues policy makers need information on are; what information is possible to provide in different countries; or what information is currently not available that is desirable for future data collection?

As access to reliable data is of such importance for implementing well-grounded education policies, many European countries have a long tradition of quantitative data collection related to different aspects of education. There are also numerous organisations working at international (e.g. OECD, UNESCO/UIS, WHO, UNICEF) and European (e.g. European Commission, Eurydice, Eurostat) levels that collect national level educational data and analyse it in different, comparative ways. Mainly, such data collections are made directly or indirectly in cooperation with national countries' official statistics producers via questionnaires or online platforms. The work of these organisations has taken many different approaches and focussed on a range of different educational topics, but it is clear that data collection related to inclusive education has been a particularly problematic area for European countries (Watkins, Ebersold \& Lénárt, 2014), even though the need for such data is well recognised (e.g. Council of the European Union, 2009).

\section{A possible model for exploring inclusive education at different system levels}

Despite the various definitions used for inclusive education and their dependency upon contextual circumstances (e.g., Florian 2014a, Loreman et al., 2014b), several attempts have been made to present different kinds of 'measuring instruments' for inclusive education. One model that intends to reflect a broader spectrum of an inclusive education system is the input - process - output model developed by Kyriazopoulou and Weber (2009), and used by Loreman et al. (2014a), and Watkins and Ebersold (2016). The model identifies three elements of the inclusive education system which are important 
dimensions to consider when collecting data intended to inform policy-makers and other stakeholders in the field of inclusive education.

The first element relates to inputs to the educational system, including all aspects provided to achieve a certain outcome. Such inputs concern, for example, resources and finances, teacher education and teacher development, qualification level of teachers, infrastructure issues, legislation and curriculum.

The second element, process, is about all the educational activities including procedures and school- or classroom-practices which transform inputs into outputs, and concern school climate, activities undertaken in the school and classroom, teaching strategies, and support provisions.

Finally, the third element is about measuring the outputs and / or outcomes of the educational input and processes. Outputs of the education refers to measures such as access to education, school attendance, social learning attainments and achievements, curricular and student achievements and participation and inclusion rates, while outcomes of the education refers to the effects, impacts or consequences of the input and/or processes, such as employability, academic and functional literacy, further educational opportunities, independency, and adaption to society (Kyriazopoulou \& Weber, 2009; Loreman, 2014).

These elements can also be linked to a multi-level dimension which builds on the different structural levels; macro, meso, and micro. The macro-level relates to the system of education, the practice and the policy of education within a country or a region. The meso-level relates to the school-level and how schools can create inclusive environments, how they value diversity, parental involvement, support provisions, local school plans and how the school leadership supports an inclusive culture and practice. The micro-level relates to the classroom level and how the organisation of learning is managed, how teachers can meet the whole range of individual needs, as well as teachers' attitudes towards inclusive settings. This level also includes the individual level of learners and their engagement and involvement with education, how they experience their schooling and their sense of belonging to the wider school-context.

The consideration of a combined, multi-dimension model indicates the different kinds of data that are needed in order to fully examine an inclusive education system. However, it can also be useful in highlighting what parts of the inclusive education system need to be focused upon for specific data collection to inform specific issues and policy questions. Overall, such a multi-dimensional model can be primarily understood as a tool for defining which parts of the inclusive education system should be or are being measured and which parts are currently overlooked.

\section{Linking the model to the concepts of presence, placement, participation, and progress}

Inclusive education can also be understood in terms of the concepts of presence, placement, participation, and progress (European Agency 2011c; Watkins, Ebersold, \& Lénárt, 2014). These concepts have also been put forward as key elements for inclusive education by Slee (2018) stating that inclusive education '....seeks to identify and dismantle barriers to education for all children so that they have access to, are present and participate in and achieve optimal academic and social outcomes from school' (p. 2). These concepts are often identified as key elements of the concept of equity (e.g., OECD, 2003). Importantly, they are also expressed as key elements for inclusive education by Ainscow (2016) arguing that inclusion is about the presence, placement, participation and achievement of all students.

Presence is about learners' access to and attendance within the education system. Presence in education thus relates to different national-level factors that facilitate or hinder learners', and especially vulnerable learners', access to education and whether a 
learner attends school or not (Watkins, Ebersold, \& Lénárt, 2014). One way to measure the level of presence in education within a country is to identify enrolment rates in education, as well as rates of out-of-school learners. Enrolment rates can be considered an outcome of the educational system at the macro-level. Similarly, access to inclusive education as measured by the enrolment rate in inclusive settings indicates another aspect of presence as an outcome at the macro-level.

Placement refers to where learners are placed within the education system, meaning to what extent they are enrolled and educated in inclusive or segregated settings. The placement of learners can be measured in terms of where they spend most of their time in school (e.g. inclusive or segregated settings). An associated factor for measuring where learners are placed is identifying who these learners are and whether they belong to risk groups (e.g. learners with SEN). The identification rate and placement of learners with SEN can also be a macro-level output of the inclusive educational system.

Participation is about the quality of the learning experience from a learner perspective, and therefore it must incorporate the views of the learners themselves (Ainscow, 2016). It relates to school-level process factors which facilitate or hinder a sense of belonging and a sense of autonomy to the learner, as well as a sense of a meaningful participation with peers of the same age. As such, participation mainly refers to processes at the meso (school or classroom) and micro (individual learner) levels.

Finally, progress refers to the results of participating in educational activities, the learning processes and outcomes across the curriculum and other outcomes such as school well-being, and what future opportunities this provides for the individual learner. Learner progress and achievement is clearly an outcome of the education system overall and can be understood from the perspective of all structural levels - micro, meso and macro.

The concepts of presence, placement, participation, and progress can be understood as a hierarchy, where presence in the education system is a prerequisite for an inclusive placement and participation, which in turn is a prerequisite for progress of any kind. This conceptualisation emphasises the importance of collecting data and sharing information concerning all levels of the inclusive educational system, not only data relating to learner or system outcomes.

\section{Inclusive education for all - the starting point for data collection}

Work with the Agency's 31 member countries (35 jurisdictions) $)^{2}$ has led to an agreed Agency Position on Inclusive Education Systems: 'The ultimate vision for inclusive education systems is to ensure that all learners of any age are provided with meaningful, high-quality educational opportunities in their local community, alongside their friends and peers" (European Agency, 2015, p. 1). The focus on all learners within inclusive education systems is a central aspect of all Agency work, including data collection activities.

Agency work has the goal of enabling policy decisions concerning inclusive education to be made based on relevant and reliable data. Alongside the Agency's wider thematic project and analysis work, the European Agency Statistics on Inclusive Education (EASIE) ${ }^{3}$ has been a long term and developmental response to this perceived need.

Highlighting the theoretical connections between different elements and structural levels of the inclusive education system, emphasises the importance of considering data collection linked to all these aspects. However, from a cross-national

\footnotetext{
${ }^{2}$ Austria, Belgium (Flemish and French communities), Bulgaria, Croatia, Cyprus, Czech Republic, Denmark, Estonia, Finland, France, Germany, Greece, Hungary, Iceland, Ireland, Italy, Latvia, Lithuania, Luxembourg, Malta, Netherlands, Norway, Poland, Portugal, Serbia, Slovak Republic, Slovenia, Spain, Sweden, Switzerland, United Kingdom (England, Northern Ireland, Scotland and Wales).

${ }^{3}$ Please see https://www.european-agency.org/data
} 
perspective, it is currently not feasible to collect data on all these dimensions from European countries (European Agency 2011c; 2018a). As a result, based on agreements with Agency member country representatives, EASIE data collection work focusses upon the concepts of presence and placement at the macro level.

Since 2012, the EASIE network of data collection experts nominated by the ministries of education (mainly statisticians working at national level) have worked collaboratively to develop agreed procedures for statistical data collection that provides national level information on agreed policy issues for inclusive education.

\section{Learners identified as having SEN - a specific focus for data collection}

Even though inclusive education is understood as being about meeting the educational needs and raising the achievements of all learners, policy makers for inclusive education across all Agency member countries agree that it is particularly important to also focus attention on specific groups of learners who are at increased risk of exclusion (European Agency, 2014b). This policy request is in line with wider research work, for example Ainscow (2016) who argues that evidence collected at the system level needs to have a specific emphasis on those groups of learners regarded to be at risk of marginalisation, exclusion or underachievement.

There are many different identified groups of learners that are at risk of marginalisation, exclusion and underachievement, such as those from different ethnic minority groups, non-native language speaking learners, refugees, and learners from a very poor socio-economic backgrounds (e.g., D'Alessio \& Cowan, 2013; Kramarczuk, Voulgarides, \& Tefera, 2017).

These vulnerable groups are important to consider and, in many countries,, these groups are included within the wider definition of 'learners with special educational needs (SEN). To date, the EASIE work has not collected specific data on specific groups of learners. Rather the focus has been upon data collecting relating to learners formally identified in countries as having special educational needs (SEN). While identification procedures and support for these learners differs widely across countries, it can be argued that: '... [learners] identified as having special needs are more likely to be excluded from school. Being part of an educational underclass places individuals and groups at risk of becoming part of a social underclass, which has long-term economic as well as social consequences, not only for those individuals and groups, but also for the rest of society. Therefore, dealing with exclusion and underachievement is not only the right thing to do, it also makes sound economic and social sense' (European Agency, 2011b. p. 15).

Therefore, the EASIE work takes inclusive education as its starting point, but then examines how countries respond to the rights of all learners to inclusive education by identifying the different placement strategies being used for learners identified as having an official decision of SEN as a specific focus (European Agency, 2018a).

\section{Background to the EASIE work}

The European Agency has collected from its member countries comparative, quantitative data on different aspects of inclusive education systems - including numbers of learners identified as having SEN - for over 20 years. In its current form - i.e. the EASIE work - data collection has taken place every second year since 2012 and covers 31 countries. In addition to statistical data, EASIE collects and presents descriptive, country background information that places the statistical data into a wider policy context.

EASIE does not have a research focus, but rather, it has a policy function and mainly serves to support policy makers' work at different levels working in the field of inclusive education. All EASIE data collection is in line with the European Union objectives for education and training (Publications Office of the European Union, 2016), 
SDG4 and the United Nations Convention on the Rights of Persons with Disabilities (UNCRPD) (United Nations, 2006).

As stated previously, there are several difficulties related to measuring and comparing complex equity issues - such as inclusive education - between countries as there are no commonly held definitions. To overcome this challenge, the EASIE work utilises agreed operational definitions (presented below) as the basis for longitudinal data on relevant indicators for inclusive education in order to be able to describe and compare how the situation looks within European countries, but also between different countries. These indicators consider the whole school population, the population of learners accessing inclusive settings and the specific population of learners with recognised special educational needs. This learner group is highlighted by all Agency member countries as presenting a specific policy priority for specific examination and attention as in all countries, to one degree or another funding mechanisms and approaches are directly linked to the identification of special or additional learning needs some learners may present (Meijer and Watkins, 2019).

The data collection methods, operational definitions and framework of indicators used within the EASIE work (European Agency, 2018a) have been co-developed with the nominated national data experts and then validated by the ministerial representatives of all Agency member countries.

An operational definition of an official decision of SEN - an official decision leads to a child/learner being recognised as eligible for additional educational support to meet their learning needs. An official decision meets the following criteria: (a) there has been an educational assessment procedure involving a multi-disciplinary team, (b) the multidisciplinary team includes members from within and external to the child's/learner's (pre)school, (c) there is a legal document which describes the support the child/learner is eligible to receive and which is used as the basis for planning, and (d) the official decision is subject to a formal, regular review process.

An operational definition of an inclusive setting - an inclusive setting refers to education where the child/learner with SEN follows education in mainstream classes alongside their mainstream peers for the largest part $-80 \%$ or more - of the school week. This proportion of time clearly indicates that a learner is placed in a mainstream setting for the majority of their time in school, and at the same time, it allows for possibilities to use small group or one-to-one withdrawal for limited periods of time (i.e. $20 \%$, or maximum 1 day a week of time in school). This operational definition has been agreed on by all member country representatives as an indicator for an inclusive placement and have been used in previous data collection work, as well as other areas of the Agency's wider work with member countries (European Agency, 2009).

For an overall review of the EASIE methodological approach, see European Agency (2018a), and for access to all country and cross-country data which the below result section refers to, see the two cross-country reports (European Agency, 2017; 2018b).

\section{Main findings from the EASIE work}

In considering the concepts presence and placement in relation to the EASIE work, the main findings of the statistical data collection can be understood in terms of the following policy issues:

a) access to mainstream education (presence)

b) access to inclusive education (presence) 
c) placement of learners identified as having an official decision of SEN. The issue of identification rates and placement of learners identified as having an official decision of SEN also concerns gender- and International Standard Classification of Education (ISCED) level breakdowns.

\section{Data regarding presence}

\section{Access to mainstream education}

This issue is essentially about learners who are and who are not in mainstream education. For most countries, this means attendance in a mainstream class in a mainstream school, or attendance in a separate special class within a mainstream school. The EASIE indicator linked to this issue shows the proportion of learners within a country that are placed in mainstream schools and are not attending fully separate special schools or for any reason are out of school or in any kind of non-formal education (as defined by the country).

Data from 2014 (school year 2012/2013) and 2016 (school year 2014/2015) shows that no country has full mainstream enrolment, meaning that within all countries there are learners not attending a mainstream school. However, most learners in all countries are attending a mainstream school.

For 2014, the total average enrolment rate in mainstream education was 97.4 percent (28 countries), while in 2016 it was 98.6 percent (29 countries).

The results also show that there is a substantial variation between countries in the enrolment rate in mainstream education, where the proportion of learners ranges from about 92 to 99 percent. Overall, the enrolment rate increased between 2014 and 2016 by about one percent across those countries with available data from both years.

Examining the enrolment rate in mainstream education must be understood as a first step to examining inclusive education systems since it is a prerequisite for further inclusive educational belonging, placement, participation and progress. However, it is important to keep in mind that enrolment in mainstream education does not say too much about the quality of the education, or how the placement and how that is experienced by the individual learner. Information on this issue is required to understand barriers and facilitators to access to education within countries.

\section{Access to inclusive education}

Data collection linked to this issue examines learners who are and who are not in inclusive education. As a result of the fact that there are different policy and practice definitions and understandings of what inclusive education means across different countries, the agreed operational definition is used for data collection. Country data indicating placement in an inclusive setting is provided in line with the $80 \%$-time placement benchmark described above and indicates which learners spend at least $80 \%$ of their time in a mainstream classroom with their peers. This indicator refers to learners' access to inclusive education and concerns the concept of presence within an inclusive setting as described above. It is about the proportion of learners within a country who are not attending separate classes in mainstream schools, fully separate special schools, are out of school or in any kind of non-formal education.

EASIE data shows that within the participating countries, no country has 100 percent enrolment in inclusive settings, meaning that all countries use some form of fully separate specialist provision (separate schools and/or units), as well as separate classes in mainstream schools. The total average enrolment rate in inclusive education in 2014 was 97.5 percent (26 countries), while in 2016 it was 98.2 percent ( 28 countries). As with the range of enrolment rate in mainstream education, the range of enrolment rate in inclusive education differs substantially between countries and ranges from about $92 \%$ to $99.5 \%$. 
The data can be said to represent a picture of how close countries are to fully inclusive attendance within their educational system, based on the operational definition of an inclusive placement.

Access to inclusive education also refers to the concept of presence in the way that it indicates the proportion of learners that are out of the inclusive system (e.g., attending a special class, special school or are out of school for more than $80 \%$ of the school time). However, as with access to mainstream education, it does not tell us too much about the quality of the inclusive education, what school practice is taking place within the system or how education is experienced by the learners.

\section{Data regarding placement}

The second dimension of EASIE data collection and analysis concerns the placement of learners with an official decision of SEN. In order to be able to map where this group of learners are placed during their time in school, a first step requires the identification of this group of learners and therefore the EASIE data shows each country's identification rate of learners recognised as having SEN. This is a complex procedure since the view of what is included in the concept of SEN varies between countries and is essentially determined by country policy, context, culture and history. To support relatively comparable data collection across countries the EASIE data collection uses the agreed operational definition of an official definition of SEN, as described above.

\section{Identification rates}

In connection with the presentation of any data on identification rates of learners with SEN, it must be recognised that the need to categorise this group of learners can result in potentially negative labelling effects. This, in turn, may be contrary to principles of inclusive education. However, as previously stated, for both the Agency country representatives, as well as noteworthy researchers (for example, Ainscow, 2016; Slee, 2018), there is a strong argument to have a specific focus on this group of learners as they are at increased risk of exclusion from mainstream education and therefore the classification process for data collection and monitoring processes is - currently unavoidable for the majority of countries.

For both 2014 and 2016, the total average of learners with an official decision of SEN across 30 countries was about 4.5 percent. However, the available data shows clear differences between countries, indicated by the identification rates ranging from about one percent to over 20 percent in 2016. This variation between countries indicates differences in countries' policies and practice for education generally and for special needs education specifically and can largely be explained by countries' different assessment procedures and financing mechanisms related to special education support.

There was no noteworthy difference in the total average of identification rates between 2014 and 2016, but within some countries there were noticeable differences.

When looking at the gender distribution of learners identified as having SEN, a very clear pattern emerges across all countries, namely that boys are identified as having SEN to a much greater extent than girls are. The distribution among boys ranges from about 60 to 74 percent, while the corresponding range for girls are about 27 to 40 percent. In total, this means that there is a boy-to-girl identification ratio corresponding to 2:1 across all countries. In other words, for every girl identified as having SEN, there are two boys identified as having SEN.

Unlike most of the results from EASIE, where there are mainly large variations between countries, the degree of the identification rate of boys and girls appears to be very similar across countries in Europe. Different explanations for this sharp difference between the genders may be possible. Firstly, it cannot be ruled out that there are more boys who have difficulties that correspond to the definition of SEN. The finding may also 
indicate that schools are failing to identify girls' special needs to the same extent as boys'. It is also conceivable that there is a conflict between the school's norms on how a learner should behave and gender, where boys to a greater extent than girls deviate from schools' standard norms and are as a result ascribed a label of SEN. The EASIE data gives no support for such speculations, but the similarities between countries are very clear, indicating that there are common causes to the skewed gender distribution across countries, which is very much in line with previous research findings (e.g., Coutinho, Oswald, \& King, 2001; Wehmeyer \& Schwartz, 2001).

The identification rate is also broken down between ISCED level 1 (primary school) and 2 (lower secondary school), in order to examine possible differences between the two levels of education. In most countries, there is a higher proportion of learners identified as having SEN in ISCED 2 than in ISCED 1. This is possibly because many learners identified as having SEN during their time in ISCED 1 retain their 'label' as requiring support when they enter ISCED 2, at the same time as there are additional learners in ISCED 2 identified as having SEN that were not identified in ISCED 1. However, overall there is not a noticeable difference in identification rates between the two ISCED levels.

\section{Placement of learners with an official decision of SEN}

Data collection around this issue looks at where learners with an official decision of SEN are placed for their education in relation to three possibilities:

- Inclusive settings - learners who are enrolled in inclusive education in line with the $80 \%$ placement benchmark, i.e. they spend $80 \%$ or more of their time in a mainstream classroom.

- Special classes - learners who are enrolled in separate special classes (for more than $20 \%$ of their time) in mainstream schools.

- Special schools - learners who are enrolled in fully separate special schools.

When combining data from learners in special classes and learners in special schools, we also look at the total number of learners that are placed in fully segregated settings. The placement issue is examined in two ways; in comparison to the whole school population, and in comparison to the population of learners with an official decision of SEN. As for the data on identification rates, the placement issue is also analysed with additional gender and ISCED level breakdowns. Each of the above placements are presented below, and an overview of the results from 2014 and 2016 is presented in Table 1. A discussion of the data in this table in relation to the different placement possibilities is presented below.

\section{Proportion of learners identified as having SEN in inclusive settings}

On the left hand side of the table is presented the different placements for learners identified as having SEN in comparison to the whole school population, while the right hand side presents the proportion of learners identified as having SEN in different placements compared to all SEN students. It can be noted that the total average of those learners placed in inclusive settings was in 2014 2.36 percent and in 2016 it was 2.73 percent. When it comes to the proportion of learners identified as having SEN placed in inclusive settings, EASIE data shows a great variation between countries, regardless of whether the comparison is made using the whole school population or with all learners with an official decision of SEN. This result shows that countries take very different approaches to providing inclusive education for learners identified as having SEN. Furthermore, results show that the proportion of learners identified as having SEN that were educated in inclusive settings across all countries in 2014 was about 53 percent, and in 2016 about 60 percent. It is also important to notice that within many countries with a 
very high identification rate of learners identified as having SEN, the vast majority of those learners in these countries are placed in an inclusive setting, indicating that a high identification rate within a country does not necessarily mean a high proportion of learners in segregated settings.

Table 1.

Placement distribution (\%) of learners with an official decision of SEN compared with the whole school population and with all learners with an official decision of SEN in 2014 and 2016.

\begin{tabular}{|c|c|c|c|c|c|c|c|c|}
\hline & \multicolumn{4}{|c|}{$\begin{array}{l}\text { In comparison to the whole school } \\
\text { population }\end{array}$} & \multicolumn{4}{|c|}{$\begin{array}{l}\text { In comparison with all learners with } \\
\text { SEN }\end{array}$} \\
\hline & $\begin{array}{c}\text { Total } \\
\text { average } \\
2014\end{array}$ & $\begin{array}{c}\text { Total } \\
\text { average } \\
2016\end{array}$ & $\begin{array}{l}\text { Range } \\
2014\end{array}$ & $\begin{array}{l}\text { Range } \\
2016\end{array}$ & $\begin{array}{c}\text { Total } \\
\text { average } \\
2014\end{array}$ & $\begin{array}{c}\text { Total } \\
\text { average } \\
2016\end{array}$ & $\begin{array}{l}\text { Range } \\
2014\end{array}$ & $\begin{array}{l}\text { Range } \\
2016\end{array}$ \\
\hline $\begin{array}{l}\text { Inclusive } \\
\text { education }\end{array}$ & 2.36 & 2.73 & $\begin{array}{l}0.14- \\
16.02\end{array}$ & $\begin{array}{l}0.12- \\
19.05\end{array}$ & 52.68 & 60.56 & $\begin{array}{l}3.46- \\
98.18\end{array}$ & $\begin{array}{l}4.98- \\
99.21\end{array}$ \\
\hline $\begin{array}{l}\text { Special } \\
\text { classes }\end{array}$ & 0.56 & 0.53 & $\begin{array}{c}0.09- \\
3.64\end{array}$ & $\begin{array}{l}0.07- \\
3.70\end{array}$ & 13.16 & 11.91 & $\begin{array}{l}1.89- \\
59.69\end{array}$ & $\begin{array}{l}2.15- \\
55.34\end{array}$ \\
\hline $\begin{array}{l}\text { Special } \\
\text { schools }\end{array}$ & 1.82 & 1.54 & $\begin{array}{c}0.09- \\
7.06\end{array}$ & $\begin{array}{c}0.03- \\
7.98\end{array}$ & 40.04 & 34.76 & $\begin{array}{l}1.74- \\
95.73\end{array}$ & $\begin{array}{c}0.79- \\
100^{1}\end{array}$ \\
\hline
\end{tabular}

${ }^{1 T}$ he data of $100 \%$ for one country included in this indicator should be viewed as an outlier, because data on learners with an official decision of SEN is only available for special classes and special schools and not for any form of inclusive placement.

Note: The number of included countries differ between kinds of placement because of missing data in some categories. The number of included countries is for (a) inclusive education $n=28$, (b) special classes $n=24$, (c) special schools $\mathrm{n}=30$.

\section{Proportion of learners identified as having SEN in special classes}

When looking at the proportion of learners identified as having SEN placed in special classes (i.e. where learners spend more than $20 \%$ of their time or more), it can be noted that about 12-13 percent of the total population of learners identified as having SEN are placed in separate special classes in mainstream schools. As with inclusive placements, there is a great variation between countries in terms of the extent to which special classes are used, indicated by the wide range shown in Table 1. This form of placement for learners identified as having SEN is reported to be the placement that is applied to the lowest degree. However, it is important to note that many countries report in their additional comments accompanying their data, that it is difficult to provide reliable data on learners in special classes. As a result, it may be that data on learners placed in special classes is under-reported or missing for some countries.

\section{Proportion of learners identified as having SEN in special schools}

Data on learners identified as having SEN placed in special schools are in most countries reported to be more reliable and easier to provide. Within all countries, there are separate special schools where some learners identified as having SEN attend. However, even more than for inclusive or special class placements, the variation differs substantially between countries. The proportion of learners identified as having SEN attending a separate special school ranges from very low (below 1 percent) to very high numbers (above 90 percent), and the total average across countries was in 201440 percent, while in 2016 it was about 35 percent, as shown in Table 1. The wide range between countries in the proportion of learners identified as having SEN in special schools 
shows that very different placement procedures and structures are being used in different countries.

Proportion of learners identified as having SEN in fully separate settings

EASIE data also looks at the proportion of learners identified as having SEN in fully segregated educational settings, that is separate special schools and special classes combined. As can be seen in Table 1, in all countries there are some learners identified as having SEN that are placed in segregated settings (special classes and/or special schools) and not having their right to an inclusive setting being met, even though the range of fully separate settings differs greatly across countries. The information on learners in fully segregated settings can be used as an indicator of certain trends and movements towards or against inclusive placements within specific countries over time, but also for comparing between countries.

In total, across countries, a large proportion of learners identified as having SEN are educated in separate non-inclusive settings, indicating that in many countries there is still the potential for the further development of more inclusive placements for learners identified as having SEN. This relatively high proportion of learners identified as having SEN placed in segregated settings, further supports the importance of having a focus of data collection on this group of learners.

The data on placements shows a great difference concerning the identification rates for boys and girls identified as having SEN. This difference is then reflected in all the different placement alternatives, showing that the gender distribution is roughly the same for all placements - inclusive, special class, or special school. About two-thirds of learners with SEN in these placements are boys, while about one-third are girls, no matter what placement is looked at.

Concerning differences of placements in educational settings between ISCED levels 1 and 2 , the data indicates that there are differences and contradictory patterns among countries, but in total there are no great differences of the placements between ISCED 1 and ISCED 2. However, there is a somewhat higher enrolment in inclusive settings and in special classes within ISCED 1, while the opposite pattern applies to enrolment in special schools.

\section{Concluding comments: possible developments in data collection for inclusive education?}

This paper has aimed to describe how some of the main results from the EASIE work can be linked to and understood in relation to equity in different system levels, as well as to the key concepts of presence and placement in inclusive education.

The available longitudinal comparative data relating to issues concerning inclusive education systems and learners identified as having SEN from around 31 countries in Europe, indicates that there are clear differences and variations between countries in how they respond to all learners' right to an inclusive education. There are also variations in the degree of identification rates of learners identified as having SEN, but also large variations between how countries choose to place these learners within their educational systems. Finally, the EASIE data also reveals a very skewed gender distribution of identification rates, where boys are much more likely to be identified as having SEN than girls.

Overall, it can be concluded that all countries use some form of fully segregated settings for some learners, indicating that all countries face the challenge of further developing their inclusive education systems. This conclusion in turn points to the 'gap' evident as a result of different starting points (Haug, 2017; Watkins \& Meijer, 2016) between inclusive education on the one hand, as a societal, equitable, democratic 
educational goal as advocated in international policy (UNESCO, 2009a, 2017), and on the other hand, how it is expressed within and across different national education systems.

To meet this challenge and in order to try to decrease this gap, countries will require future data collection at the macro level which further contributes to the understanding and development of relevant information for different stakeholders and policy makers working in the field of inclusive education at different levels.

In looking at the availability of data at national, European and international levels, there is a need for additional data at the macro level in order to get a completer and more comprehensive picture of the inclusive education system. Possibilities for developing existing data collection in relation to the concepts of presence and placement should be examined. European Agency work with member countries indicates that it is particularly important to find working definitions that are valid and agreed upon across countries concerning learners who are out of school (European Agency, 2018c; Soriano, Watkins and Ebersold, 2017).

Further and different types of data is required that explores the concepts of participation and progress, in line with Slee (2018) who argues that future data collection should not be limited, but instead, be expanded to include comprehensive data collection on educational experiences of learners and their feelings concerning different educational placements. Data collection also needs to be expanded in line with Schuelka's (2018) conclusions that state that there is a need to expand data collection to also include measures of educational quality, outcomes, and experiences.

Developing data collection frameworks to comprehensively cover presence, placement, participation and progress issues requires both quantitative and qualitative data collection methods which together can capture the characteristics and the elements that describe and identify learners' experiences and perceptions of inclusive and/or segregated educational placements. Such comprehensive data collection is a clear aim for work at the national level in countries. Whilst it may be beyond the scope of international and European data collection frameworks more complete national datasets informing presence, placement, participation and progress issues would be a key driver for informing future developments to data collection at the international and European levels.

\section{Acknowledgement:}

The authors wish to acknowledge the contributions of András Lénárt (European Agency staff member) for his contributions to the EASIE work and this article.

\section{References}

Ainscow, M. (2016). Diversity and Equity: A Global Education Challenge. New Zealand Journal of Educational Studies, 51(2), 143-155.

Artiles, A. J., Kozleski, E. B., Dorn, S., \& Christensen, C. (2006). Learning in inclusive education research: Re-mediating theory and methods with a transformative agenda. Review of Research in Education, 30(1), 65-108.

Council of the European Union. (2009). Council conclusions of 12 May 2009 on a strategic framework for European cooperation in education and training (ET2020) (2009/C119/02).

Council Recommendation of 22 May. (2018). Promoting common values, inclusive education, and the European dimension of teaching. ST/9010/2018/INIT. OJ C 195, 7.6.2018, p. $1-5$.

Coutinho, M. J., Oswald, D. P., \& King, M. (2001). Differences in the special education identification rates for boys and girls: Trends and issues. Richmond, VA: Project PROGRESS, Virginia Commonwealth University.

D'Alessio, S., \& Cowan, S. (2013). Cross-cultural approaches to the study of "inclusive" and "special needs" education. In A. W. Wiseman (Ed.), Annual Review of 
Comparative and International Education 2013 (pp. 227-261). Emerald Group

Publishing Limited.

Disabilities. Study commissioned by the Policy Department C: Citizens' Rights and

Constitutional Affairs, European Parliament.

DOI: $10.1080 / 13603116.2019 .1623330$

European Agency for Development in Special Needs Education. (2009). Special Needs

Education Country Data 2008. Odense, Denmark: European Agency for

Development in Special Needs Education.

European Agency for Development in Special Needs Education. (2011a). Participation in inclusive education: A framework for developing indicators. Odense, Denmark:

European Agency for Development in Special Needs Education.

European Agency for Development in Special Needs Education. (2011b). Teacher

Education for Inclusion Across Europe - Challenges and Opportunities. Odense,

Denmark: European Agency for Development in Special Needs Education.

European Agency for Development in Special Needs Education. (2011c). Mapping the

Implementation of Policy for Inclusive Education: An exploration of challenges and

opportunities for developing indicators. Odense, Denmark: European Agency for

Development in Special Needs Education.

European Agency for Special Needs and Inclusive Education. (2014a). Inclusive education

in Europe: Putting theory into practice. International Conference, 18 November

2013. Reflections from researchers. Odense, Denmark: European Agency for

Special Needs and Inclusive Education.

European Agency for Special Needs and Inclusive Education. (2014b). Organisation of

Provision to Support Inclusive Education - Summary Report. (V.J. Donnelly and M.

Kyriazopoulou, eds). Odense, Denmark: European Agency for Special Needs and Inclusive Education

European Agency for Special Needs and Inclusive Education. (2015). Agency Position on

Inclusive Education Systems. Odense, Denmark: European Agency for Special

Needs and Inclusive Education.

European Agency for Special Needs and Inclusive Education. (2017). European Agency

Statistics on Inclusive Education: 2014 Dataset Cross-Country Report. (J. Ramberg,

A. Lénárt, and A. Watkins, eds.). Odense, Denmark: European Agency for

Special Needs and Inclusive Education.

European Agency for Special Needs and Inclusive Education. (2018a). European Agency

Statistics on Inclusive Education: Methodology Report-Updated 2018. (A. Lénárt, J.

Ramberg and A. Watkins, eds.). Odense, Denmark: European Agency for Special

Needs and Inclusive Education.

European Agency for Special Needs and Inclusive Education. (2018b). European Agency

Statistics on Inclusive Education: 2016 Dataset Cross-Country Report. (J. Ramberg,

A. Lénárt, and A. Watkins, eds.). Odense, Denmark: European Agency for

Special Needs and Inclusive Education.

European Agency for Special Needs and Inclusive Education. (2018c). European Agency

Statistics on Inclusive Education: Key Messages and Findings (2014 / 2016).

(A. Watkins, J. Ramberg and A. Lénárt, eds.). Odense, Denmark: European

Agency for Special Needs and Inclusive Education.

European Commission. (2015). Education and Training Monitor, 2015. Luxembourg:

Publications Office of the European Union.

European Commission. (2018). Education and Training Monitor, 2018. Luxembourg:

Publications Office of the European Union. 
European Union. (2018). Council Recommendation on promoting common values, inclusive education, and the European dimension of teaching. Official Journal of the European Union.

Florian, L. (2014a). What counts as evidence of inclusive education? European Journal of Special Needs Education, 29(3), 286-294.

Göransson, K., \& Nilholm, C. (2014). Conceptual diversities and empirical shortcomings-a critical analysis of research on inclusive education. European Journal of Special Needs Education, 29(3), 265-280.

Hardy, I. \& Woodcock, S. (2015). Inclusive Education Policies: Discourses of Difference, Diversity and Deficit. International Journal of Inclusive Education 19(2), 141-164.

Haug, P. (2017). Understanding inclusive education: ideals and reality. Scandinavian Journal of Disability Research, 19(3), 206-217.

Hollenweger, J. (2014). Beyond categories and labels. Knowledge to support assessment for learning. In L. Florian (Ed.), The Sage handbook of special education (2nd ed.). London: Sage.

Kramarczuk Voulgarides, C., \& Tefera, A. (2017). Reframing the racialization of disabilities in policy. Theory into Practice, 56(3), 161-168.

Kyriazopoulou, M. \& Weber, H. (2009). Development of a set of indicators - for inclusive education in Europe. Odense, Denmark: European Agency for Development in Special Needs Education.

Loreman, T. (2014). Measuring inclusive education outcomes in Alberta, Canada. International Journal of Inclusive Education, 18(5), 459-483.

Loreman, T., Forlin, C. \& Sharma, U. (2014a). Measuring indicators of inclusive education: A systematic review of the literature. In C. Forlin \& T. Loreman (Eds.), Measuring Inclusive Education (pp. 165-187). Bingley, UK: Emerald.

Loreman, T., Forlin, C., Chambers, D., Sharma, U., \& Deppeler, J. (2014b). Conceptualising and measuring inclusive education. In C. Forlin \& T. Loreman (Eds.), Measuring inclusive education (pp. 3-17). Bingley, UK: Emerald.

Meijer, C., \& Watkins, A. (2016). Changing conceptions of inclusion underpinning education policy. In Implementing Inclusive Education: Issues in Bridging the PolicyPractice Gap (pp. 1-16). Emerald Group Publishing Limited.

Meijer, C., \& Watkins, A. (2019): Financing special needs and inclusive education - from Salamanca to the present, International Journal of Inclusive Education,

OECD (2003) Diversity, inclusion and equity: insights from special needs provision, Education Policy Analysis, 9-37.

Publications Office of the European Union, 2016. EU cooperation in education and training (ET 2020). Luxembourg: Publications Office. https://eur-lex.europa.eu/legalcontent/EN/TXT/?uri=LEGISSUM\%3Aefo016 (Last accessed February 2019).

Schuelka, M, J. (2018). Implementing inclusive education. Helpdesk Report. Knowledge, evidence and learning for development.

https://opendocs.ids.ac.uk/opendocs/bitstream/handle/123456789/14230/374 Implementing_Inclusive Education.pdf? sequence $=1$ \&isAllowed $=\mathrm{y}$ (Last accessed February 2018).

Slee, R. (2018). Defining the scope of inclusive education. Paper commissioned for the 2020 Global Education Monitoring Report, Inclusion and education.

Soriano, V., Watkins, A., \& Ebersold, S. (2017). Inclusive education for learners with UNESCO. (2009a). Inclusive education: The way of the future. Final report from the international conference on education. Geneva: UNESCO, International Bureau of Education.

UNESCO. (2009b). Policy guidelines on inclusion in education. Paris: UNESCO. 
UNESCO. (2015). Incheon Declaration and Framework for Action: Ensure inclusive and equitable quality education and promote lifelong learning opportunities for all. Paris: UNESCO.

UNESCO. (2017). A guide for ensuring inclusion and equity in education. Paris: UNESCO.

United Nations. (2006). Convention on the Rights of Persons with Disabilities.

www.un.org/development/desa/disabilities/convention-on-the-rights-ofpersons-with-disabilities.html (Last accessed February 2019)

Watkins, A \& Meijer, C.J.W. (2016). Implementing Inclusive Education: Issues in Bridging the Policy-Practice Gap. Emerald Group Publishing Limited.

Watkins, A., \& Ebersold, S. (2016). Efficiency, effectiveness and equity within inclusive education systems. In Implementing Inclusive Education: Issues in Bridging the Policy-Practice Gap (pp. 229-253). Emerald Group Publishing Limited.

Watkins, A., Ebersold, S., \& Lénárt, A. (2014). Data collection to inform international policy issues on inclusive education. In Measuring Inclusive Education (pp. 53-74). Emerald Group Publishing Limited.

Wehmeyer, M. L., \& Schwartz, M. (2001). Disproportionate representation of males in special education services: Biology, behavior, or bias? Education \& Treatment of Children, 24(1), 28-28.

World Health Organisation (WHO). 2011. World report on disability. Geneva: WHO.

\begin{abstract}
About the Authors
Joacim Ramberg has been a European Agency for Special Needs and Inclusive Education staff member since 2016 and has conducted policy-related research and datacollection on inclusive education in relation to EASIE. He holds a $\mathrm{PhD}$ in Special Education and currently works as a senior lecturer in Special Education at Stockholm University. His research interest revolves around issues such as inclusive education, school development, democracy and social justice.

Amanda Watkins is Assistant Director with the European Agency for Special Needs and Inclusive Education. She is responsible for a number of European level activities and co-ordinates Agency activities focussing upon country policy review and development, including the European Agency statistical data collection. She has a PhD in Education, MA in Education, and BEd in Special Education. She has published widely at the European and international levels.
\end{abstract}

